\title{
VERIFICATION OF THE PHYSICAL LOAD IN WORK OF NURSES IN SLOVAKIA AND POLAND
}

doi:10.2478/mape-2018-0111

Date of submission of the article to the Editor: 04/2018

Date of acceptance of the article by the Editor: 07/2018

MAPE 2018, volume 1, issue 1, pp. 883-887

Ing. Ivana Cechova

University of Zilina, Slovakia

Joanna Bartnicka, PhD., Eng.

Silesian University of Technology, Poland

doc. Ing. Luboslav Dulina, PhD.

University of Zilina, Slovakia

\begin{abstract}
Musculoskeletal complaints represent a common occupational problem for health care workers throughout the world. This study provides shortened results of review by Nordic Questionnaire, which was modified for review reasons. The aim of the study is verification of work-related load Slovak and Polish nurses in their work and mutual comparison of the results. Comparison of statistical sample of Slovak nurses (468) and Polish nurses (48 for this moment) points to certain common features in the field of pain and the determination of their causes. Verification of the knowledge base of nurses in the field of ergonomics, principles of manipulation of load and kinestetika shows slightly better results for Polish nurses. The study will continue to compare larger statistical samples, identify the most common pains and their causes to the reason prevent them.
\end{abstract}

Keywords: Slovak nurses, Polish nurses, physical load, MSD,

\section{INTRODUCTION}

Physical load in work of nurse can have serious consequences for employee health. The work of a nurse is consider for physically demanding activity (Pedan et al., 2017). Research on the physical load of nursing work is a typical topic throughout the world (Plinta and Krajcovic, 2015). Particularly Musculoskeletal Disorders (MSD) represent a common occupational problem in the nursing profession and a regular research area for safety improvements (Smith et al., 2006). A high prevalence of work-related musculoskeletal disorders has been observed among nursing personnel in all settings of patient care, including hospitals, long-term care, and home health care (Schall et al., 2016). Various risk factors have been documented (Krkoska et al., 2017). They include occupational factors such as work environment, manual handling, heavy lifting, repetitive work, and strenuous tasks (Smith et al., 2004). Physical capabilities (such as muscle mass and therefore muscular strength) that enable people to cope with physical job demands naturally undergo an age-related decline over time (Voorbij and Steenbekkers, 2001). Thus, an increased risk of MSD for elderly nurses seems plausible, because throughout a working life there could be a growing discrepancy between individual's physical capabilities and physical job demands (Heiden et al., 2013). However, MSD in nurses begin to appear in after a few years in the profession, which can be considered as evidence of the existing risk of developing an occupational disease. The topic physical load in work of nurse has been studied in different countries including the USA, the UK, France, Sweden, Japan, etc. Therefore, this study aims to investigate the prevalence of MSDs for nurses in Slovakia and Poland and their comparison. 


\section{METHODOLOGY}

The survey was conducted in each country in the same way. In Slovakia and in Poland, nurses were approached through a modified Nordic Questionnaire. The questionnaire was retrieved and processed by The University of lowa, Institute of Preventive and Clinical Medicine in Bratislava. This questionnaire was modified especially for review reasons.

The Nordic Questionnaire is anonymous, designed to gain information on the occurrence of musculoskeletal disorders work-related (Wiecek and Wiecek, 2018). Based on the data from the completed questionnaires, the situation is further analysed and individual ergonomic analyses are carried out (Gasova et al., 2017).

The questionnaire has three main parts by default. The first part - general information - is aimed at gaining information about the person being self-assessed. The questionnaire is anonymous, so the person does not give his name. This section is focused on getting information about the nurse's profile (age, height, weight, prevailing work posture, number of years in the profession, etc.).

In the second part - subjective assessment of the difficulties with the musculoskeletal system - the questionnaire focuses on gaining information about the physical difficulties of the nurse. Nurse in the questionnaire gradually marks the parts of the body, in which she felt the pain for the past 12 months. It can also mark if she visits a doctor or physiotherapist due the pain of part the body. In the questionnaire, it is possible to mark problems with parts of the body such as neck, lower back, upper back, shoulders, elbows, hands and wrists, hips and thighs, ankles and feet.

In the third part - subjective assessment of the reaction to specific situations - there are situations that can occur during the nurse's profession. The nurse using for assessment of situation the Borg scale (from 0 to 10, where 0 represents no load and 10 heavy load) which indicates how large is the perceived load arising from specific situations. This section is aimed at verifying the perception of the workload from the nurse's perspective in the context of her work. For example, when working tasks such as manipulating heavy objects or patients, the work in the same working postures for a long time, physically demanding work, the quality of working tools and handling aids, and so on.

The fourth part added - knowledge and use of terms - was designed to test the nurse's knowledge. In this part the nurse marks whether she knows respectively uses the following terms: ergonomics, principles of handling difficult objects or patients, kinestetics, principle of fixed parts and gaps. All terms refer to patient manipulation. This section is aimed at verifying the knowledge base of the nurses.

\section{RESULTS}

The results have two parts: results from hospitals in Slovakia and results from hospitals in Poland. For Slovak hospitals are available complete results, the number of results (number of answers from nurses) is 468 . For Poland hospitals are available only partially results because the research in this country is only at the start.

Research is focused on nurses work in bed care units. These units were selected for the reason of presupposes the most work-related physical load.

The total number of respondents from Slovakia hospitals was adjusted to 468. These respondents were from 15 different departments of hospitals and from homes of social services. In the statistical sample, 466 women and 2 men of all age categories were evaluated. The number of years in the profession ranged from 3 months to 49 years. $78 \%$ of the nurses (365 persons) determined the position of alternating sitting and standing as a predominant working position. $18 \%$ of the nurses (83 persons) determined the prevailing working position to be standing. Less than $1 \%$ ( 6 persons) determined the prevailing position to be sitting. The other $3 \%$ of nurses did not comment on this issue.

The total number of respondents of Polish hospitals is 46 to that moment. These respondents are from 4 different departments of hospitals. Statistical sample is consist of 45 women and 1 
man, of all age categories. The number of years in the profession ranged from 2 years to 40 years, what is similarly interval as in Slovak nurses. $61 \%$ of the nurses (28 persons) determined the position of alternating sitting and standing as a predominant working position. $31 \%$ of the nurses (14 persons) determined the prevailing working position to be standing. No one determined the prevailing position to be sitting. The other $8 \%$ of nurses did not comment on this issue.

The comparison of results from Slovakia and Poland hospitals is only partially possible, from the reason that results from Poland hospitals are only $10 \%$ of results from Slovakia hospitals. So, in this phase of the research is possible to say that nurses in Slovakia and Poland are suffer from similarly pains. Results second part of questionnaire - subjective assessment of the difficulties with the musculoskeletal system - for Slovak and Polish nurses are shown on Fig. 1.

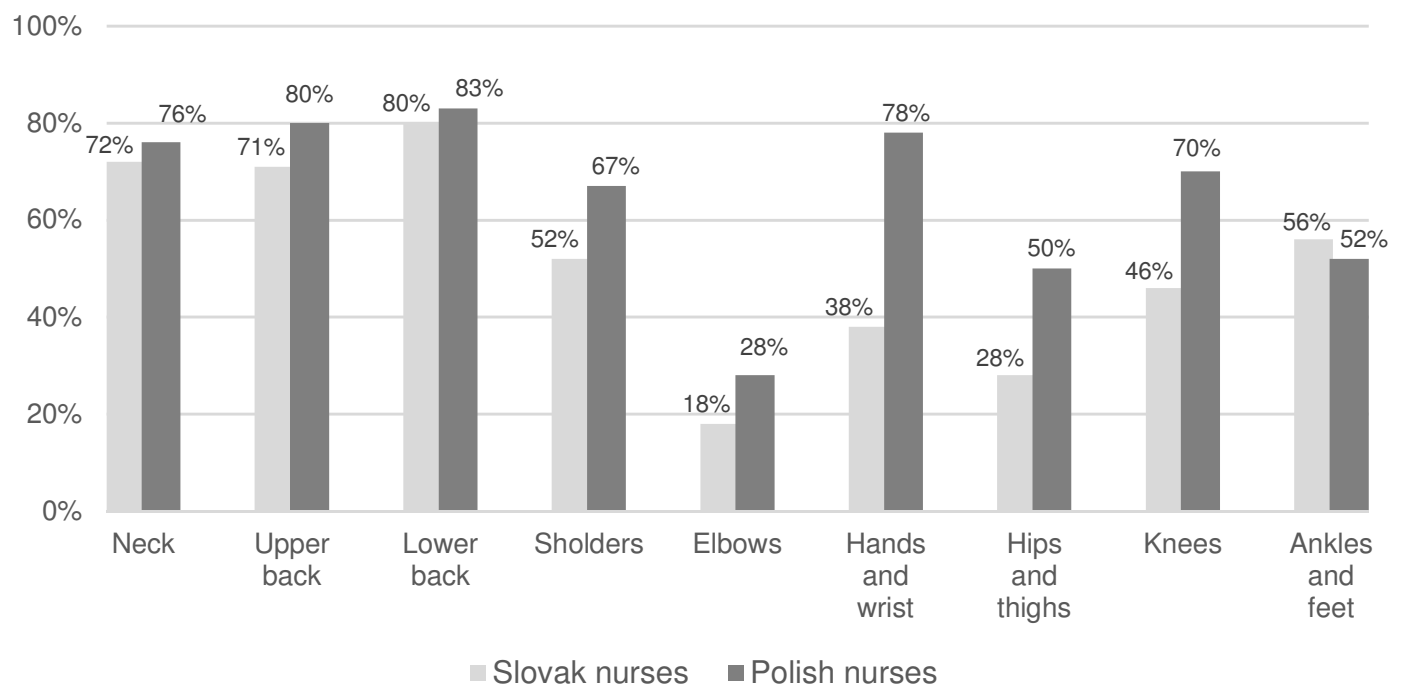

Fig. 1. The incidence of pain in a statistical sample of Slovak and Polish nurses

The lower part of the back is marked as the most loaded part of the body for both countries. The second one is marked part of the upper back and third one part of the neck. In other parts of the body can be observed differences. The most visible difference can be observed for part of the body - hand and wrist. While nurses in Slovak hospitals do not greatly report problems with their hands and wrists, nurses in Polish hospitals report often these problems. You can see more significant differences in body parts - hips and thighs and knees.

Results of the third part of the questionnaire - subjective assessment of the reaction to specific situations - are shown on Table 1.

From the average load values for specific situations, nurses from Slovak hospitals are the most loaded due to hurry during working operations (load value $=7$ ), insufficient rest breaks during work change (load value $=7$ ) and due to the lifting and carrying of heavy objects, respectively patients (load value $=7$ ). Lesser load (load value $=6$ ) the nurses feel due to work in an uncomfortable or forced working position due to long-term work in the same positions, forced labor or dialing of the hull and the impact of physically demanding work on the limit of their forces. The same loads also cause them overtime, irregular changes and long working hours and lack of quality or lack of handling aids. Microclimate conditions at the workplace such as excessive heat, cold, humidity as well as the insufficient quality of work tools cause the nurses a load of $=5$. The smallest load (load value $=4$ ) in the nursing work is caused by working with your hands above your head or away from your body, as well as inadequate training. 
Table 1

Average values of load in specific situations

\begin{tabular}{|l|c|c|}
\hline \multicolumn{1}{|c|}{ Situation } & \multicolumn{2}{c|}{ Average values } \\
\cline { 2 - 3 } & Slovak nurses & Polish nurses \\
\hline 1. Hurry up in performing work operations, time pressure. & 7 & 9 \\
\hline 2. Insufficient breaks during the work shift. & 6 & 8 \\
\hline 3. Work in an uncomfortable or forced working posture. & 7 & 9 \\
\hline $\begin{array}{l}\text { 4. Long-term work in the same working positions (standing, tilting, kneeling, } \\
\text { etc.). }\end{array}$ & 6 & 9 \\
\hline 5. Work in forcibly inclined, inclined and dialed hull to the sides. & 6 & 9 \\
\hline 6. Work at the limit of your physical strength, physically demanding work. & 6 \\
\hline 7. Work with your hands over your head or away from your body. & 4 & 9 \\
\hline 8. Heat, cold, humidity on the workplace. & 5 & 7 \\
\hline 9. Lifting, wearing, carrying heavy objects / patients. & 7 \\
\hline 10. Overtime, irregular work shifts, long working hours. & 6 & 9 \\
\hline 11. Insufficient quality of working tools (badly handled, not enough). & 5 & 7 \\
\hline 12. Insufficient quality of handling equipment / missing handling equipment. & 6 \\
\hline 13. Insufficient training and training for the proper performance of work. & 4 & 6 \\
\hline
\end{tabular}

In general, nurses in Polish hospitals experience a greater load caused by the same situations as nurses in Slovak hospitals. Nurses are the most loaded due to hurry up in performing work operations, work in an uncomfortable or forced working posture, long-term work in the same working positions, work in forcibly inclined, work at the limit of your physical strength and lifting, wearing, carrying heavy objects / patients (load value $=9$ ). Nurses feel high level of load due to insufficient breaks during the work shift $($ load $=8)$. Work with hands over head or away from body, heat, cold, humidity on the workplace, overtime, irregular work shifts, long working hours and insufficient quality of handling equipment or missing handling equipment nurses average marked as load level $=7$. Insufficient quality of working tools (load value $=6$ ) and insufficient training and training for the proper performance of work (load value $=5$ ) are marked by nurses of the lowest level of load.

The last part of questionnaire - knowledge and use of terms - is shown that Polish nurses have better knowledge base. Polish nurses know better and understand the concepts of ergonomics, principles of manipulation with load, kinestetika and principles of fixed parts and gaps. The difference between Polish and Slovak nurses is not large (1 to 10\%) but concerns all the above-mentioned notions.

\section{DISCUSSION}

Objectivity in diagnosing MSDs is difficult to achieve as complaints may arise without any physical findings and physical findings may remain without complaints (Heiden et al., 2013). Most studies are exclusively based on self-reporting questionnaires to assess both exposures and health effects. Our study is one them. It is completely subjective assessment of self-problems with musculoskeletal system. Assessment of situations which may occur in nursing work and review of nurses knowledge.

The most frequent MSD in our study for Slovak and Polish nurses are disorders of the lower back. Low back pain is a regular occupational problem for nurses worldwide. This problem has been previously reported at rates in England $45 \%$ nurses (Smedley et al., 1995), Australia $63 \%$ nurses (Lusted et al., 1994), Sweden 64\% nurses (Josephson et al. 1997) or China 56\% nurses (Smith et al., 2004). Similarly, are detected seriously problems among Slovak and Polish nurses with upper back. MSD of the upper back was reported by one-third (33.9\%) of Japanese nurses, which is higher than an investigation from Sweden (30\%) (Josephson et al. 1997), but lower than another study of Asian nurses conducted in China (37\%) (Smith et al., 2004). Many of Slovak and Polish nurses marked problems with shoulders and neck too. As can be seen from the second part of our study, the problems that nurses point to may be caused by situations that the nurses have indicated as most loadsome. They are above all 
lifting and carrying of heavy objects respectively patients and work in an uncomfortable or forced working position.

\section{CONCLUSION}

This study is only halfway. Our aim is to get enough of the answers from Polish hospitals so they that can be compare with answers from Slovak hospitals. Consequently, common causes of the emergence of MSD will be sought and a search for solutions to prevent them.

Overall, our study has shown that MSDs are occur among Slovak and Polish hospital nurses, particularly lower back and upper back pain. In the part of questionnaire, which is focus on situations in work of nurse are identified possible causes of MSD.

Therefore, to help alleviate considerable MSD load in work of nurse, a greater emphasis will need to be placed work organization, and occupational stress, as well as the more traditional hazard reduction strategies such as manual handling, work tasks, and other occupational factors. The introduction of patient-lifting devices such as cranes and hoists may also be worthwhile in areas where patients are regularly handled.

It is really important to care for nurses because they care for patients and their health. If nurses will suffer from occupational diseases, they will not be able to care for patients and this can have serious consequences.

\section{ACKNOWLEDGEMENT}

This research was supported by VEGA project [1/0936/16] entitled Using tools of digital factory for development of ergonomic prevention programs.

\section{REFERENCES}

Gasova, M., Gaso, M. and Stefanik, A. (2017). Advanced Industrial Tools of Ergonomics Based on Industry 4.0 Concept. Procedia Engineering, Volume 192, pp. 219-224.

Heiden, B., Weigl, M., Angerer, P. and Müller, A. (2013). Association of age and physical job demands with musculoskeletal disorders in nurses. Applied Ergonomics, Volume 44, pp. 652-658.

Josephson, M., Lagerström, M., Hagberg, M. and Hjelm, E.W. (1997) Musculoskeletal symptoms and job strain among nursing personnel: A study over a three year period. Occupational and Environmental Medicine, Volume 54, pp. 681-685.

Krkoska, L., Gregor, M. and Matuszek, J. (2017). Simulation of human effect to the Adaptive Logistics System used in public facilities. Procedia Engineering, Volume 192, pp. 492-497.

Lusted, M.J., Carrasco, C.L., Mandryk, J.A. and Healey, S. (1994). Self reported symptoms in the neck and upper limbs in nurses. Applied Ergonomics, Volume 27, pp. 381-387.

Pedan, M., Gregor, M. and Plinta, D. (2017). Implementation of Automated Guided Vehicle System in Healthcare Facility. Procedia Engineering, Horny Smokovec, Volume 192/2017, pp. 665-670.

Plinta, D. and Krajcovic, M. (2015). Production System Designing with the Use of Digital Factory and Augmented Reality Technologies. International Conference on Automation, Wroclaw, Volume 350, pp. 187-196.

Schall, M.C.Jr., Fethke, N.B. and Chen, H. (2016). Working postures and physical activity among registered nurses. Applied Ergonomics, Volume 54, pp. 243-250.

Smedley, J., Egger, P., Cooper, C. and Coggon, D. (1995). Manual handling activities and risk of low back pain in nurses. Occupational and Environmental Medicine, Volume 52, pp. 160-163.

Smith, D.R., Mihashi, M., Adachi, Y., Koga, H. and Ishitake, T. (2006). A detailed analysis of musculoskeletal disorder risk factors among Japanese nurses. Journal of Safety Research, Volume 37, pp. 195-200.

Smith, D.R., Wei, N., Kang, L. and Wang, R. (2004). Musculoskeletal disorders among professional nurses in mainland China. Journal of Professional Nursing, Volume 20, pp. 390-395.

Smith, D.R., Wei, N., Zhao, L. and Wang, R.S. (2004). Musculoskeletal complaints and psychosocial risk factors among Chinese hospital nurses. Occupational Medicine, Volume 54, pp. 579-582.

Voorbij, A.I.M. and Steenbekkers, L.P.A. (2001). The composition of a graph on the decline of total body strength with age based on pushing, pulling, twisting and gripping force. Applied Ergonomics, Volume 32, pp. 387-292.

Wiecek, D. and Wiecek, D. (2018). Production Costs of Machine Elements Estimated in the Design Phase. Intelligent Systems in Production Engineering and Maintenance ISPEM 2017, Volume 637, pp. 380-391. 